\title{
The effect of regional politics on regional life expectancy in Italy (1980-2010)
}

\author{
MARCEL F. JONKER ${ }^{1,2}$, EDOARDO D'IPPOLITO ${ }^{3}$, TERJE A. EIKEMO ${ }^{1,4}$, \\ PETER D. CONGDON ${ }^{5}$, NICOLA NANTE ${ }^{3}$, JOHAN P. MACKENBACH ${ }^{1}$ \\ \& CARLIJN B.M. KAMPHUIS ${ }^{1}$
}

${ }^{1}$ Department of Public Health, Erasmus University Medical Centre, Rotterdam, The Netherlands, ${ }^{2}$ Department of Health Policy and Management, Erasmus University, Rotterdam, The Netherlands, ${ }^{3}$ Department of Public Health, Health Services Research Laboratory, University of Siena, Italy, ${ }^{4}$ Department of Sociology and Political Science, Norwegian University of Science and Technology, Trondheim, Norway, and 5 School of Geography, Queen Mary University of London, London, UK

\begin{abstract}
Background: The evidence on the association between politics and health is scarce considering the importance of this topic for population health. Studies that investigated the effect of different political regimes on health outcomes show inconsistent results. Methods: Bayesian time-series cross-section analyses are used to examine the overall impact of regional politics on variations in Italian regional life expectancy (LE) at birth during the period 1980-2010. Our analyses control for trends in and unobserved determinants of regional LE, correct for temporal as well as spatial autocorrelation, and employ a flexible specification for the timing of the political effects. Results: In the period from 1980 to 1995, we find no evidence that the communist, left-oriented coalitions and Christian Democratic, centre-oriented coalitions have had an effect on regional LE. In the period from 1995 onwards, after a major reconfiguration of Italy's political regimes and a major healthcare reform, we again find no evidence that the Centre-Left and Centre-Right coalitions have had a significant impact on regional LE. Conclusion: The presented results provide no support for the notion that different regional political regimes in Italy have had a differential effect on regional LE, even though Italian regions have had considerable and increasing autonomy over healthcare and health-related policies and expenditures.
\end{abstract}

Key Words: Population health, politics, life expectancy, Italy

\section{Introduction}

There has been growing interest in the association between politics and health [1]. Studies have investigated to what extent different political regimes are associated with various health outcomes, such as suicide rates, self-rated health, and life expectancy (LE) at birth. These studies generally compare countries with a different political tradition and show that progressive or social-democratic (i.e. leftoriented) regimes have a positive effect on health outcomes relative to other political regimes [2-10].
The latter is usually explained by the fact that democratic, left-oriented regimes tend to favour egalitarian ideologies and implement more redistributive and preventive (health) policies, which have a positive effect on population health [11].

This study adds to the current evidence base by investigating to what extent differences in regional political regimes (i.e. governments with a 'left', 'centre', or 'right' political orientation) can explain inter-regional health differences within a single

Correspondence: Marcel F. Jonker, Department of Public Health, Erasmus University Medical Centre, PO Box 2040, 3000 CA, Rotterdam, The Netherlands. E-mail: marcel@mfjonker.com

(Accepted 21 November 2016) 
country. Italy is a particularly interesting case for such a comparative analysis. First, all 20 Italian regions as shown in Figure 1 are defined by manifold historical, geographical, and socio-economic differences [12-14]. At the political level, Italian regions have been characterised by different political regimes over time, each enjoying considerable and increasing autonomy in health policy matters. Moreover, in our 30-year study period (which covers

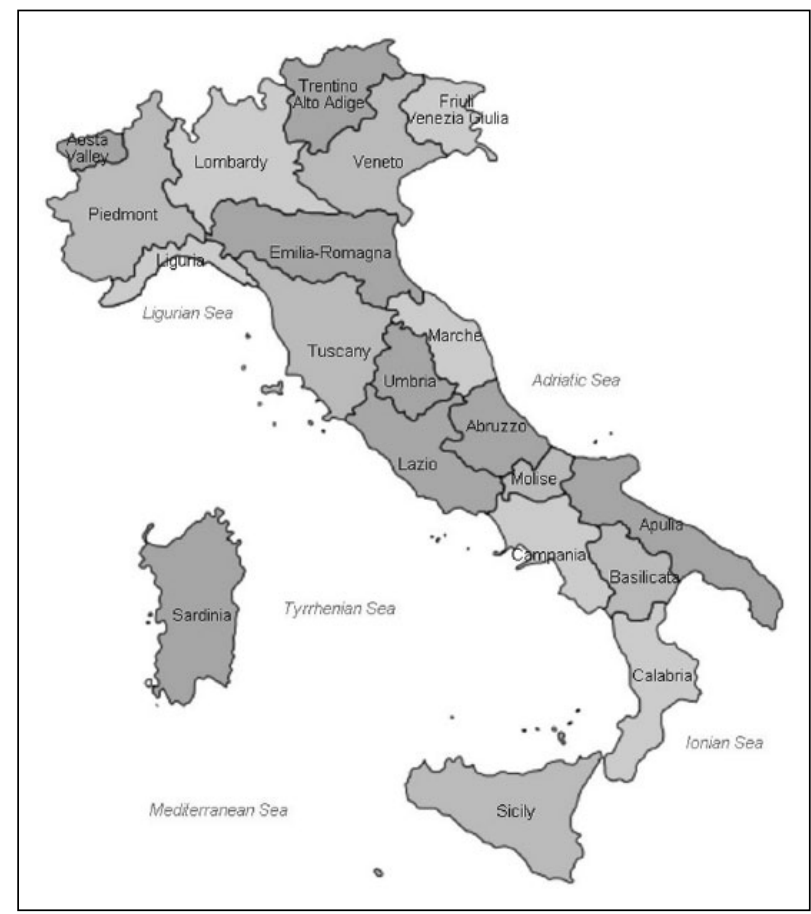

Figure 1 . The 20 regions of Italy. the 1980-2010 period), considerable inter-regional differences in lifespan can be observed. It is unknown to what extent these can be attributed to the different political regimes, economic conditions, or other variations between regions; for instance, with respect to cultural factors. For all these reasons, Italy constitutes an interesting analysis of the effect of regional politics on regional population health.

We hypothesise that the political orientation of regional governments in Italy has had an effect on LE at birth, assuming that the main causal pathway goes from politics to health (see Figure 2). Also, in line with Lundberg et al. [15], we argue that it is the institutions, the programmes, and the resources they provide to citizens that matter, not the label attached to the government parties. Drawing upon the work of Starfield [16,17], we understand the political context as several interacting systems of policies: occupational policies, social policies, economic policies, and health policies. These systems of policies influence specific practices in different non-political subsystems, in terms of power relationships, behavioural or cultural characteristics, environmental characteristics, the social distribution of wealth, and, above all, the health system. All of these societal factors have been studied with respect to LE [2$5,10,18]$, highlighting sufficiently plausible pathways from politics to population health.

To investigate the overall effect of regional politics on regional LE in Italy, Bayesian time-series crosssection regressions are used that control for temporal and spatial autocorrelation in the data and can control for a range of unobserved and observed confounders. Moreover, the implemented regressions

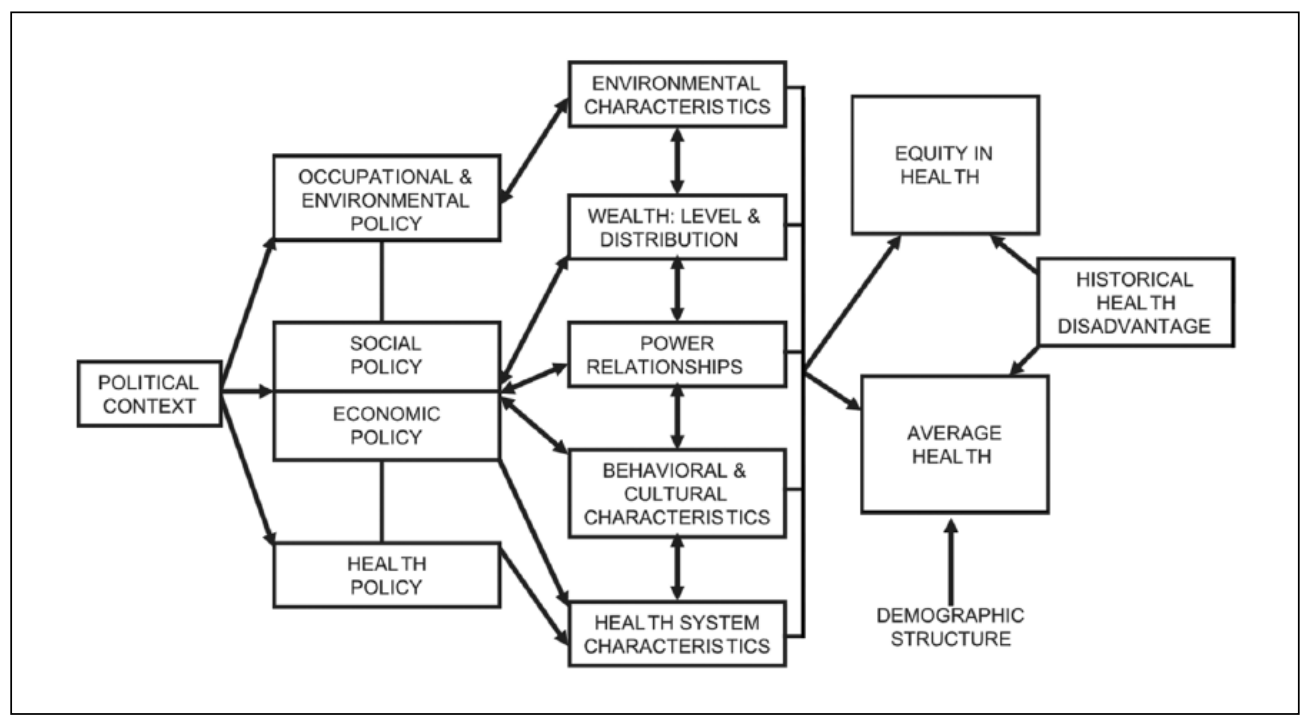

Figure 2. Pathways linking the political context to population health. Source: adopted from Starfield [17]. 
Box 1. Description of political regimes in Italy.

Until 1995:

- Italian Communist Party (left): a left regime, oriented to increase workers' rights and a redistribution of wealth, relatively anticapitalist and free-trade oriented;

- Christian Democratic (centre): a moderately conservative, centre-oriented regime, partly influenced by socialism, inspired by Christianity and Catholic oriented, relatively capitalist oriented;

From 1995 onwards:

- Centre-right coalition: moderately conservative, Catholic oriented, stronger supporter of family values, more oriented towards commercial interests and economic liberalism, and privatisation of State's goods in general (roughly analogous to the American Republicans and the British Conservatives);

- Centre-Left coalitions: relatively progressive and social-democratic, more oriented towards social liberalism, social welfare, environmental issues, and less towards privatisation of State's goods (roughly analogous to the American Democratic and the British Labour Party).

accommodate great flexibility in the timing of the political effects. The latter ensures reliable estimates of the political effects that are independent of a predefined lag-structure. Accordingly, the presented methodology is well-suited to estimate the average (i.e. longer-term) impact of regional political regimes on regional population health.

\section{Data and methods}

\section{Background}

Between 1945 and 1994, Italian politics was dominated by two major political regimes: the first led by the Christian Democratics (Democrazia Cristiana (DC)) and the second by the Italian Communist Party (Partito Comunista Italiano (PCI)). During the early $1990 \mathrm{~s}$, the collapse of communism and the exposure of a massive corruption scheme in Italy initiated a major political crisis, which resulted in a dramatic reconfiguration of political parties - both at the national and at the regional level [19]. Consequently, from 1995 onwards, two political poles emerged: the Centre-Right and Centre-Left coalitions. Box 1 provides a synthetic description of the Italian political regimes.

During the period under analysis (i.e. 19802010), regional governments have had considerable sovereignty regarding regional healthcare provision. Since 1978, with the establishment of the National Health Service (Servizio Sanitario Nazionale $(\mathrm{SSN})$ ), regional governments have been in charge of healthcare provision - albeit subject to guidelines determined by the Ministry of Health to ensure equal access and quality of care [20,21]. During the early 1990s, the mounting political crisis and increased public deficits culminated into a major reform of the SSN. In 1992-1993, legislation was approved that aimed to promote the efficiency and quality of the healthcare system and to make the regional governments more sensitive to the need to control aggregate healthcare expenditure. To achieve the latter, the central government ceded even more responsibility to the regional governments and essentially retained only limited coordination and supervisory powers over healthcare and healthrelated policies [22]. Hence, from 1995 onwards, regional governments have had substantially more influence on the provision of healthcare, implementation of preventative healthcare policies, and on the financing of the healthcare system. Moreover, since a major constitutional reform in 2001, regional governments have obtained legislative powers in all matters that are not directly under the central government's remit, including education, the provision of social welfare and land, and environment governance tasks. Accordingly, regional political regimes have had considerable and increasing autonomy over policies that can affect regional LE during the period under analysis, although still subject to guidelines and minimum standards as determined by the central government $[23,24]$.

\section{Data}

To investigate the effect of regional political regimes on regional LE in Italy, data on the composition of the regional governments from 1975 to 2011 were constructed based on carefully selected sources (see the online appendix). Figure 3 provides a graphical representation of the political regimes over time and shows that there is substantial variation over time and between regions. The figure also shows that a few regions and/or time periods are characterised by political regimes that do not conform to the regimes as described in Box 1; these are represented by a separate category referred to as 'other'.

For the statistical analyses, the information in Figure 3 was summarised by a set of dummy variables with separate dummies used for the DC, PCI, Centre-Left, and Centre-Right regimes. This implicitly allowed for a structural break in 1995, which exactly coincides with the transformation of the healthcare system. Also for the 'other' category, separate effects for before and after 1995 were specified. 


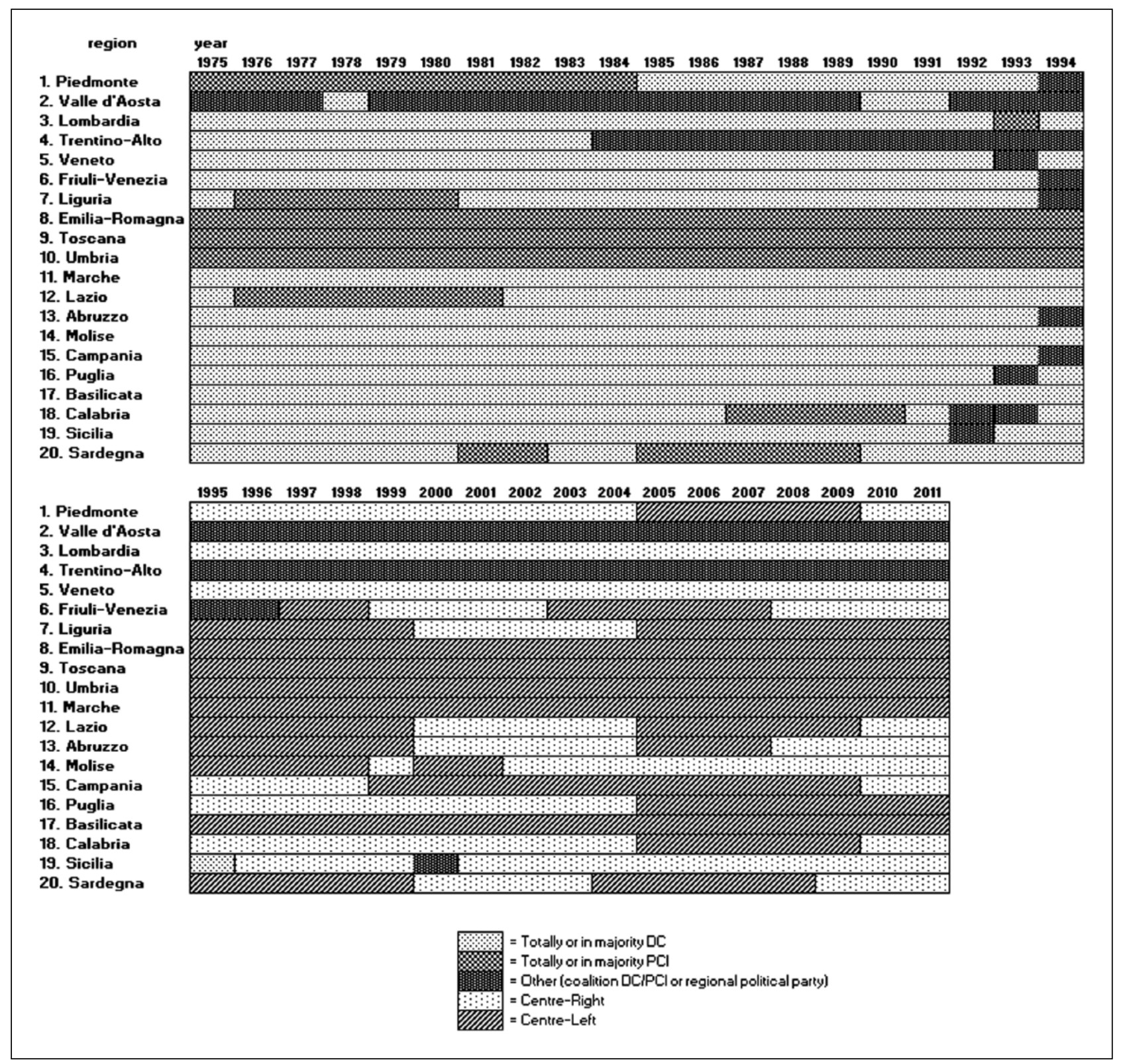

Figure 3. Composition of regional governments (Giunta Regionale), Italy, 1975-2011.

Annual LE at birth for men and women for all 20 Italian regions was calculated for the same period. The required population and mortality data were obtained from the Italian National Institute of Statistics (ISTAT), with 2010 being the most recent year for which regional mortality information was publicly available [25].

Finally, regional real Gross Domestic Product (GDP) per capita was calculated for the period 1977-2009 using data obtained from ISTAT. Because GDP per capita does not have an instantaneous effect on LE and small reductions in GDP per capita are not immediately translated into decreasing LE, a lagged three-year moving average GDP per capita variable was used [26]. This better reflects the general trend in regional GDP per capita, which is a potential confounder and hence included in the regressions.

\section{Methods}

The impact of regional political regimes on regional LE is investigated using Bayesian time-series crosssection regressions with region-specific intercepts (i.e. a fixed-effects specification). The region-specific intercepts capture all unobserved differences between 


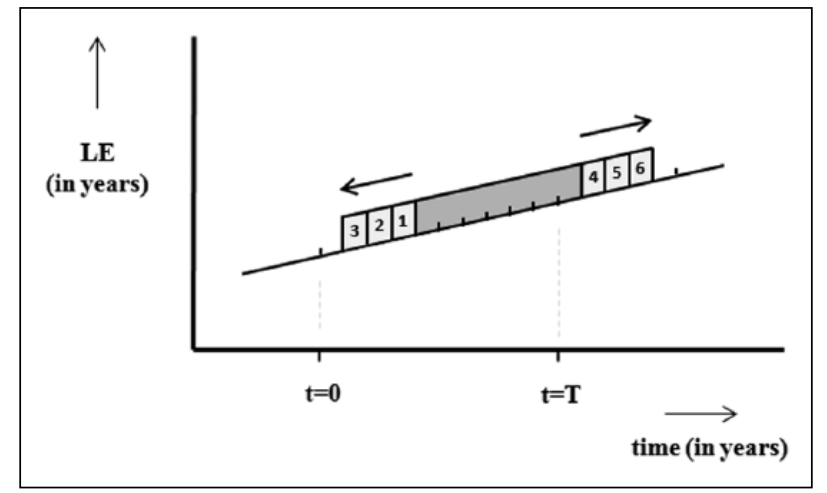

Figure 4. Measuring the average impact of regional political regimes on regional life expectancy using a flexible lag structure. $\mathrm{t}=0$ denotes the moment that a political regime comes into power, and $\mathrm{t}=\mathrm{T}$, the moment that the political regime is no longer in power in this particular region. The dark grey area represents the average political effect in the period in which the political effect is always measured (i.e. the fixed period), whereas the lighter grey areas capture the same effect in the optionally included preceding and ensuing years. As can be seen, the average effect of the political regime is in Figure 4 assumed to be positive (relative to the omitted regime).

Italian regions that are constant over time. To additionally control for unobserved common time effects, which reflect unobserved effects on LE that are variable over time and common to all Italian regions, a parsimonious yet flexible combination of a linear time trend with a full set of optionally included time dummies was used. The time dummies are optionally included using Gibbs variable selection [27] and capture all significant deviations from the linear trend. Furthermore, to control for spatial and temporal autocorrelation the statistical model accommodates first-order spatial and temporal autocorrelation. Finally, the model includes the lagged three-year moving average regional real GDP per capita as a potential confounder and a set of dummies that represent the presence of political regimes during the 1980-2010 period.

Figure 4 provides a graphical representation of the political specification. As can be seen, the development of LE over time for the omitted political regime is depicted as a linear trend (for simplicity) and the impact of the other political regimes is measured as the average deviation from this trend over a longer period of time. Using data for a single region, these deviations would not be identifiable. However, making use of the panel structure of the data, similarities and differences between regions do allow for the measurement of political effects. Importantly, the implemented approach avoids an a priori specification of the correct lag structure for the political effects (indeed, we assume the absence of instantaneous effects of regional politics on population health). Instead, a 'fixed' period is defined for political regimes that are in power for at least five consecutive years, with up to three preceding and three ensuing years that are optionally included based upon the information in the data. This allows the political effects to range from years $2-5$ after the political regimes have come into power until years $2-5$ after the political regimes are no longer in power.

The model specification is programmed in the BUGS language and estimated using OpenBUGS, which implies that estimation and inference follow a Bayesian approach [28-30]. Appendix 1 contains the model code and full specification of the prior distributions. We used proper priors that are much more diffuse than the posterior distributions, except for the pseudo-priors in the time dummy selections, which are supposed to be informative [31], and which were specified based upon the results of an almost saturated model without the optional inclusion of the time dummies.

The model was fitted separately for male and female LE. Each estimation started with 50,000 burn-in Markov Chain Monte Carlo (MCMC) iterations to allow the Markov chains to converge, followed by a total of 225,000 MCMC iterations to reliably approximate the posterior distributions. Convergence was evaluated using the Gelman et al. [32] criteria based on three parallel chains. To improve convergence, the panel-specific intercepts were not estimated, but instead removed from the data via first-differencing. This induces negative first-order autocorrelation, which was accommodated for using the Prais-Winsten approach [33].

\section{Results}

The estimated LEs are summarised in Figure 5, which depicts the development of regional LE over time. As can be seen, LE has increased markedly in all Italian regions, but there are substantial differences in LE between the various regions.

Table I provides the estimation results. After controlling for the (lagged) GDP per capita, common time effects, and temporal as well as spatial autocorrelation, we find no significant effect of regional political regimes on Italian LE. The coefficients of the Christian Democratic regimes in the period before 1995 are consistently negative for both males and females, but insignificantly different from zero as indicated by the $95 \%$ credible intervals that comprise zero. In the period from 1995 onwards, the coefficients for the Centre-Right political regimes are close to zero and insignificant for both males and females - as again indicated by the $95 \%$ credible 


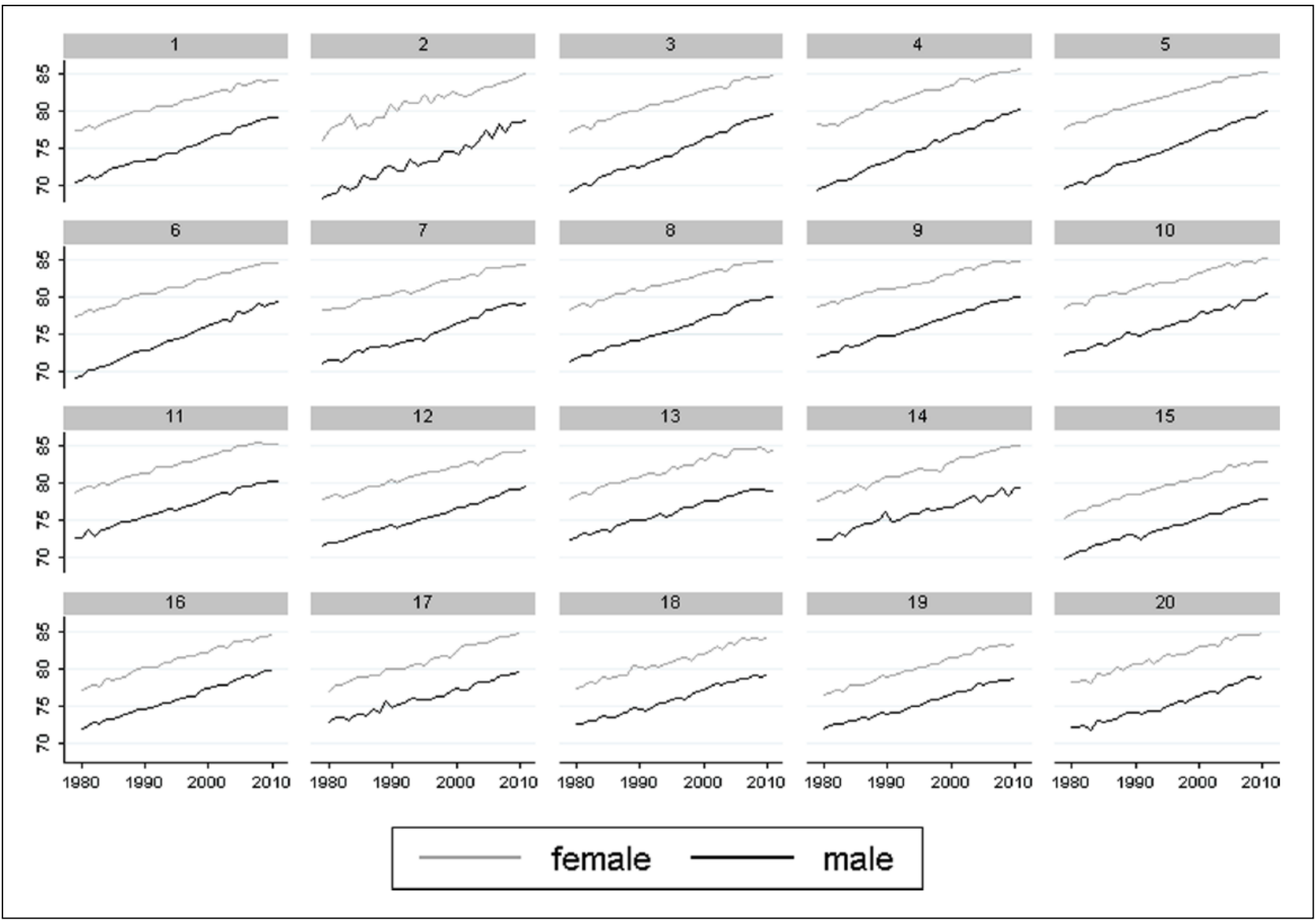

Figure 5. Regional male and female life expectancy, Italy, 1978-2010.

Table I. Regression results.

\begin{tabular}{|c|c|c|c|c|}
\hline \multirow[b]{2}{*}{ Before 1995: } & \multicolumn{2}{|c|}{ Male LE } & \multicolumn{2}{|c|}{ Female LE } \\
\hline & & & & \\
\hline - Christian Democratic (relative to the Italian Communist Party) & -0.01 & $(-0.14-0.12)$ & -0.02 & $(-0.13-0.12)$ \\
\hline - Other (relative to the Italian Communist Party) & 0.28 & $(-0.45-0.81)$ & 0.20 & $(-0.28-0.66)$ \\
\hline \multicolumn{5}{|l|}{ After 1995: } \\
\hline - Centre-Right (relative to Centre-Left) & 0.01 & $(-0.10-0.12)$ & 0.00 & $(-0.10-0.11)$ \\
\hline - Other (relative to Centre-Left) & -0.13 & $(-19.4-19.0)$ & -0.33 & $(-19.1-18.7)$ \\
\hline 3-year averaged real GDP & -0.03 & $(-0.17-0.11)$ & 0.02 & $(-0.10-0.14)$ \\
\hline Linear trend & 0.28 & $(0.26-0.30)$ & 0.24 & $(0.22-0.27)$ \\
\hline rho 1 (temporal autocorrelation) & -0.41 & $(-0.49-0.34)$ & -0.38 & $(-0.47-0.30)$ \\
\hline rho 2 (spatial autocorrelation) & 0.32 & $(0.20-0.45)$ & 0.35 & $(0.21-0.50)$ \\
\hline$R$-squared & 0.41 & $(0.33-0.48)$ & 0.47 & $(0.39-0.53)$ \\
\hline \multicolumn{5}{|l|}{ Number of time dummies included: } \\
\hline - With posterior probability $>0.05$ & 12 & & 14 & \\
\hline - With posterior probability $>0.50$ & 4 & & 6 & \\
\hline
\end{tabular}

Bayesian 95\% credible intervals in parentheses.

intervals that comprise zero. Finally, the coefficients for the 'other' political regimes are positive in the period before 1995 and negative in the period from 1995 onwards, and statistically insignificant in both periods.

\section{Discussion}

Over the last three decades, there has been important and significant variation in LE at birth between Italian regions, both for men and women. In the 
period before 1995, we find no statistically significant evidence that the communist, left-oriented regime was associated with higher regional LE. In the period after 1995, we again find no evidence that Centre-Left political regimes were associated with higher regional LE.

On the one hand, our findings seem to contradict the general evolution of Italy's system of government that has, from the early 1970 s onwards, witnessed a clear devolution of legislative and executive power from the central government to the Italian regions [24]. As previously mentioned, this general trend included many competences that are expected to influence regional health and LE; for example, the provision of healthcare and its financing, social policies, and welfare [34], but also education and environmental conditions, for instance via the protection from air pollution, the tutelage of water sources and (agricultural) land, the provision of waste management, and the monitoring of environmental standards [35].

On the other hand, the apparently limited differential impact of regional politics on regional LE is certainly partially attributable to the coordinating role that the central government traditionally had and continues to have on regional policies. For example, even though the principal locus of health-policy making shifted towards the regions during the 1990s [22], the Basic Levels of Care (BLC) was introduced in order to achieve minimum standards and a degree of uniformity in the provision of healthcare across Italian regions [36]. The same kind of minimum standards and coordinating role of the central government can be observed in education and social welfare [37].

Regardless of the explanation, our study has shown that regional political regimes have apparently, despite the substantial and increasing autonomy of the Italian regions, not been able to achieve a better relative outcome in terms of LE.

\section{Strengths and weaknesses}

Our study has several important limitations. First, estimating the average effect of political regimes on regional LE over a longer period of time made it impossible to differentiate between various direct and indirect political effects [5]. Consequently, even though it is the institutions, legislations, programmes, and resources that regimes provide to their citizens that truly affect LE $[15,38,39]$, our study can only determine the extent to which broadly defined regimes have been able to achieve - on the whole - a better relative outcome; although, it should be noted that the latter was the research question at hand.
Second, even though LE at birth is, for various reasons, an attractive outcome measure for health comparisons between smaller geographic areas [40], it only describes the mortality experience of the regional populations and does not reflect differences in the morbidity experience of those being alive [41]. Alternative summary measures of population health, such as healthy or health-adjusted LE, are likely more informative about average population health $[42,43]$, but the required health-status survey data were unavailable for the period under investigation. Also, alternative outcome measures, such as age-standardised avoidable mortality, may be more sensitive to changes in regional politics and provide a better dependent variable in our analysis [44]. The required data, however, were unavailable for the earlier part of the period under investigation. Finally, the fixed effects in our estimations are - by design - collinear to the political effects of regions that experience little to no change in their political regimes over time. Given that several regions indeed experience little political change (see Figure 3), our specification has less statistical power to establish significant political effects than otherwise obtained from a dataset with 20 regions covering a 30-year time period. By using a fixed-effects approach, we thus preferred unbiased effect estimates over statistical efficiency, which is based on the manifold unobserved cultural, geographical, and historical differences between the included regions that we could otherwise not adequately control for.

The study also has some major strengths. First and foremost, the study employed Bayesian timeseries cross-section models that directly controlled for many observed and unobserved factors and trends that, besides political regimes, have an effect on regional LE. For example, fixed effects were specifically included to control for all structural variation between regions that remained constant over time; for example, cultural and historical differences. Furthermore, all effects that changed over time and affected all Italian regions simultaneously were picked up by the common time effects. Additionally, effects that changed over time but only affected a few adjacent regions (e.g. an influenza epidemic in the north or a major heat wave in the south) were picked up by the spatial error terms. Differences in economic development between the different regions were subsequently controlled for using the included GDP per capita variable. Finally, any remaining effects were captured by the standard error terms, excluding the effects that correlated with the timing of the changes in political regimes, which were picked up by the political specifications. Given the substantive controls for potential confounders, the political 
specification is unlikely to reflect any random/spurious correlations.

Regarding the political specifications, a second strength of the study was the use of a Bayesian specification that avoided the need to a priori specify the correct timing of the political effects. Instead, the specifications automatically accommodated a flexible lag structure and thereby allowed for uncertainty in the parameters, as well as in the correct model specification. Being able to fit such models is a particular advantage of a Bayesian estimation framework. Finally, we were able to obtain detailed data on the different political regimes in all 20 Italian regions over a considerable period of time, and able to collect data on LE at birth as the outcome measure in this study, which is preferred over other more subjective and less reliable indicators, such as self-rated health [45] and standardised mortality ratios [40].

\section{Conclusion}

Our results indicate that different regional political regimes in Italy have not been able to achieve a better relative outcome in terms of LE. An important feature of the study is that we have demonstrated how Bayesian times-series cross-section models can be used to analyse the impact of regional political regimes on health outcomes, which can be used to investigate the impact of regional political regimes on other outcome measures as well. Further research is required to confirm our results for other and possibly more sensitive health outcomes, such as, for example, age-standardised avoidable mortality.

\section{Declaration of conflicting interests}

None declared.

\section{Funding}

This work was supported by the European Community in the framework of the European Community Action Scheme for the Mobility of University Student (ERASMUS) project (to EI) and by the European Community in the framework of the EURO-GBD-SE project (project number 101059, to TAE).

\section{References}

[1] Muntaner C, Borrell C, Ng E, et al. Politics, welfare regimes, and population health: controversies and evidence. Sociol Health Illn 2011;33:946-64.

[2] Navarro V, Muntaner C, Borrell C, et al. Politics and health outcomes. Lancet 2006;368:1033-7.

[3] Page A, Morrell S and Taylor R. Suicide and political regime in New South Wales and Australia during the 20th century. f Epidemiol Community Health 2002;56:766-72.
[4] Shaw M, Dorling D and Smith GD. Mortality and political climate: how suicide rates have risen during periods of Conservative government, 1901-2000. F Epidemiol Community Health 2002;56:723-5.

[5] Mackenbach JP and McKee M. Social-democratic government and health policy in Europe: a quantitative analysis. Int f Health Serv 2013;43:389-413.

[6] Bennema-Broos M, Groenewegen PP and Westert GP. Social democratic government and spatial distribution of health care facilities. The case of hospital beds in Germany. Eur F Public Health 2001;11:160-5.

[7] Borrell C, Espelt A, Rodriguez-Sanz M, et al. Politics and health. $\mathcal{F}$ Epidemiol Community Health 2007;61:658-9.

[8] Espelt A, Borrell C, Rodríguez-Sanz M, et al. Inequalities in health by social class dimensions in European countries of different political traditions. Int $\mathcal{F}$ Epidemiol 2008;37(5):1095-105.

[9] Mackenbach JP, Hu Y and Looman CW. Democratization and life expectancy in Europe, 1960-2008. Soc Sci Med 2013;93:166-75.

[10] Mackenbach JP. Political conditions and life expectancy in Europe, 1900-2008. Soc Sci Med 2013;82:134-46.

[11] Navarro V (ed). The political and social contexts of health. Amityville, New York: Baywood Publishing Company, Inc., 2004.

[12] Ferragina E. The socio-economic determinants of social capital and the mediating effect of history: Making Democracy Work revisited. Int f Comp Sociol 2013;54(1):48-73.

[13] Baccile $G$ and Valerio $M$. The 150 years anniversary of Italy: a memorandum from the South. Assist Inferm Ric: AIR 2010;30(2):110-12.

[14] Bonati $M$ and Campi R. What can we do to improve child health in southern Italy? PLoS Medicine 2005;2(9):e250.

[15] Lundberg O, Yngwe MÅ, Stjärne $M K$, et al. The role of welfare state principles and generosity in social policy programmes for public health: an international comparative study. Lancet 2008;372(9650):1633-40.

[16] Starfield B. What can we learn from equity research and interventions? Aust F Prim Health 2004;10(3):7

[17] Starfield B. Pathways of influence on equity in health. Soc Sci Med 2007;64(7):1355-62.

[18] Helmert U, Streich W and Borgers D. Regional differences in trends in life expectancy and the influence of the political and socioeconomic contexts in Germany. Int $\mathcal{F}$ Health Serv 2003;33(4):669-86.

[19] Bull MJ and Rhodes M. Between crisis and transition: Italian politics in the 1990s. West European Politics 1997;20(1):1-13. DOI:10.1080/01402389708425172

[20] Piperno A and Di Orio F. Social differences in health and utilization of health services in Italy. Soc Sci Med 1990;31(3):305-12.

[21] Giannoni $M$ and Hitiris T. The regional impact of health care expenditure: the case of Italy. Appl Econ 2002;34(14): 1829-36.

[22] France G. Health technology assessment in Italy. Int $\mathcal{F}$ Technol Assess 2000;16(02):459-74.

[23] Lo Scalzo A, Donatini A, Orzella L, et al. Italy: health system review. Health Systems in Transition 2009;11(6):1-216.

[24] Gruppo di Pisa. Dibattito aperto sul diritto e la giustizia costituzionale, Italy, 2012. http://www.gruppodipisa.it/ wp-content/uploads/2012/09/VivaldiDEF.pdf (accessed January 2017).

[25] Istituto Nazionale di Statistica [National Institute of Statistics] Italy, 2012. http://dati.istat.it/Index.aspx\# (accessed January 2017).

[26] Granados JAT. Politics and health in eight European countries: a comparative study of mortality decline under social democracies and right-wing governments. Soc Sci Med 2010;71(5):841-50. 
[27] Dellaportas P, Forster JJ and Ntzoufras I. On Bayesian model and variable selection using MCMC. Stat Comput 2002;12(1):27-36.

[28] Congdon P. Applied Bayesian modelling. England: John Wiley \& Sons, 2003.

[29] Ntzoufras I. Bayesian modeling using WinBUGS. Hoboken, NJ: John Wiley Sons, 2011.

[30] Lunn D, Jackson C, Best N, et al. The BUGS book: a practical introduction to Bayesian analysis. Boca Raton, FL: CRC Press, 2012.

[31] O'Hara RB and Sillanpää MJ. A review of Bayesian variable selection methods: what, how and which. Bayesian Analysis 2009;4(1):85-117.

[32] Gelman A, Carlin JB, Stern HS, et al. Bayesian data analysis. London: Chapman \& Hall, London, 1995.

[33] Prais SJ and Winsten CB. Trend estimators and serial correlation. Cowles Commission Discussion Paper, 1954.

[34] Bertolini A, Del Gaudio D and Graziano P. The national governance of social cohesion policies national report Italy. Milan: Department of Policy Analysis and Public Management Bocconi University, 2011.

[35] Pasqualini Salsa C. Diritto ambientale [Environmental right]. 9th ed. Rimini: Santarcangelo di Romagna, 2009.

[36] Lispi L, Ceccolini C, Galadini M, et al. Rapporto nazionale di monitoraggio dei livelli essenziali di assistenza [National report on the monitoring of basic levels of care]. Rome: Ministry of Health, 2011.

[37] Kazepov Y, Arlotti M, Barberis E, et al. Rescaling social welfare policies in Italy. Urbino: European Centre for Social Welfare Policy and Research, 2006.
[38] Lundberg O. Commentary: politics and public healthsome conceptual considerations concerning welfare state characteristics and public health outcomes. Int $\mathcal{f}$ Epidemiol 2008;37(5):1105-8.

[39] Pega F, Kawachi I, Rasanathan K, et al. Politics, policies and population health: a commentary on. Soc Sci Med 2013;30:1e4.

[40] Jonker MF, Van Lenthe FJ, Congdon PD, et al. Comparison of Bayesian random-effects and traditional life expectancy estimations in small-area applications. Am F Epidemiol 2012; 152:929-37.

[41] Murray CJL, Salomon JA and Mathers C. A critical examination of summary measures of population health. $B$ World Health Organ 2000;78(8):981-94.

[42] Mathers CD, Salomon JA, Murray CJL, et al. Alternative summary measures of population health. In: Murray CJL and Evans DB (eds) Health systems performance assessment: debates, methods and empiricism. Geneva: World Health Organization, pp.319-34.

[43] Jonker MF, Congdon PD, van Lenthe FJ, et al. Small-area health comparisons using health-adjusted life expectancies: a Bayesian random-effects approach. Health Place 2013;23:70-8.

[44] Quercioli C, Messina G, Basu S, et al. The effect of healthcare delivery privatisation on avoidable mortality: longitudinal cross-regional results from Italy, 1993-2003. F Epidemiol Commun H 2013;67:132-8.

[45] Huijts T, Perkins JM and Subramanian SV. Political regimes, political ideology, and self-rated health in Europe: a multilevel analysis. PLoS One 2010;5:e11711.

\section{Appendix 1. OpenBUGS model code}

model \{

\# $\mathrm{I}=20$ regions

$\# \mathrm{~T}=30$ years (first-differenced)

\# LIKELIHOOD

for (i in $1: \mathrm{I})\{$

\# first observation: Prais-Winsten

d1Y $[\mathrm{i}, 1] \sim \operatorname{dnorm}(\operatorname{mu} 1[\mathrm{i}], \operatorname{tau} 1[\mathrm{i}])$

mu1[i] <- pred[i,1] + rho[2] * sum(adj_error[index[i]: (index[i+1] -1),1 ] ) / numNeigh[i]

tau1 [i] <- tau[i] * $(1-$ pow $($ rho $[1], 2))$

\# all other observations:

for $(\mathrm{t}$ in $2: \mathrm{T})\{$

$\mathrm{d} 1 \mathrm{Y}[\mathrm{i}, \mathrm{t}] \sim \operatorname{dnorm}(\mathrm{mu}[\mathrm{i}, \mathrm{t}], \operatorname{tau}[\mathrm{i}])$

$\# \mathrm{mu}[\mathrm{i}, \mathrm{t}]<-$ plain prediction + rho[1] * error in previous year + rho[2] * average error of the surrounding areas

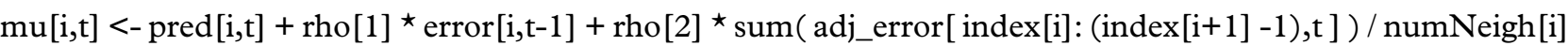

3\}

\section{\# PRED \& ERROR}

for $(\mathrm{i}$ in $1: \mathrm{I})\{$

for $(\mathrm{t}$ in $1: \mathrm{T})\{$

\# note: sum of products is faster than the OpenBUGS "inprod" function

pred $[i, \mathrm{t}]<-\operatorname{sum}($ product $[\mathrm{i}, \mathrm{t}, \mathrm{]})$

error $[i, t]<-d 1 Y[i, t]-\operatorname{pred}[i, t]$

\}) 


\section{\# PRODUCT}

for (i in $1: \mathrm{I})\{$

for $(t$ in $1: T)\{$

\# d1.Political dummies for DCI

product $[\mathrm{i}, \mathrm{t}, 1]<-$ beta $[1]$ * d1Polit $[\mathrm{i}, \mathrm{t}, 1]$ * ind [1] * ind [2] * ind [3]

product $[\mathrm{i}, \mathrm{t}, 2]<-$ beta $[1] \star$ d1Polit $[\mathrm{i}, \mathrm{t}, 2] *$ ind $[1] *$ ind $[2]$

product $[i, t, 3]<-$ beta $[1]{ }^{\star}$ d1 Polit $[i, t, 3] \star$ ind $[1]$

product $[\mathrm{i}, \mathrm{t}, 4]<-$ beta $[1] *$ d1 Polit $[\mathrm{i}, \mathrm{t}, 4]$

product $[\mathrm{i}, \mathrm{t}, 5]<-$ beta $[1] \star$ * $\mathrm{d} 1$ Polit $[\mathrm{i}, \mathrm{t}, \mathrm{5}]$ * ind $[4]$

product $[\mathrm{i}, \mathrm{t}, 6]<-$ beta $[1] * \mathrm{~d} 1$ Polit $[\mathrm{i}, \mathrm{t}, 6] *$ ind $[4] *$ ind $[5]$

product $[\mathrm{i}, \mathrm{t}, 7]<-$ beta $[1]$ * d1Polit $[\mathrm{i}, \mathrm{t}, 7]$ * ind [4] * ind [5] * ind [6]

\# d1.Political dummies for Centre Right

product $[\mathrm{i}, \mathrm{t}, 8]<-$ beta[2] * d1Polit $[\mathrm{i}, \mathrm{t}, 8]$ * ind [1] * ind [2] * ind[3]

product $[\mathrm{i}, \mathrm{t}, 9]<-$ beta $[2] \star \mathrm{d} 1$ Polit $[\mathrm{i}, \mathrm{t}, 9]$ * ind $[1] *$ ind $[2]$

product $[\mathrm{i}, \mathrm{t}, 10]<-$ beta $[2] \star \mathrm{d} 1$ Polit $[\mathrm{i}, \mathrm{t}, 10]{ }^{\star}$ ind $[1]$

product $[i, t, 11]<-$ beta $[2] \star$ d1Polit $[\mathrm{i}, \mathrm{t}, 11]$

product $[i, t, 12]<-$ beta $[2] \star$ d 1 Polit $[\mathrm{i}, \mathrm{t}, 12]{ }^{\star}$ ind $[4]$

product $[\mathrm{i}, \mathrm{t}, 13]<-$ beta[2] ${ }^{\star} \mathrm{d} 1$ Polit $[\mathrm{i}, \mathrm{t}, 13] \star$ ind $[4] \star$ ind $[5]$

product $[\mathrm{i}, \mathrm{t}, 14]<-$ beta $[2]$ * d1Polit $[\mathrm{i}, \mathrm{t}, 14]$ * ind [4] * ind [5] * ind [6]

\}

for $(\mathrm{t}$ in $1: 15)\{$

\# d1.Political dummies for 'Other' category before 1995

product $[i, t, 15]<-$ beta[3] * d1Polit $[i, t, 15]$ * ind [1] * ind[2] * ind[3]

product $[\mathrm{i}, \mathrm{t}, 16]<-$ beta[3] ${ }^{\star} \mathrm{d} 1$ Polit $[\mathrm{i}, \mathrm{t}, 16]{ }^{\star}$ ind $[1] *$ ind $[2]$

product $[i, t, 17]<-$ beta[3] * d1Polit $[\mathrm{i}, \mathrm{t}, 17]]^{\star}$ ind [1]

product $[\mathrm{i}, \mathrm{t}, 18]<-$ beta $[3]$ * d1Polit $[\mathrm{i}, \mathrm{t}, 18]$

product $[i, t, 19]<-$ beta[3] * d1Polit $[\mathrm{i}, \mathrm{t}, 19]{ }^{\star}$ ind $[4]$

product $[\mathrm{i}, \mathrm{t}, 20]<-$ beta[ $[3] * \mathrm{~d} 1$ Polit $[\mathrm{i}, \mathrm{t}, 20]{ }^{\star}$ ind $[4] *$ ind [5]

product $[\mathrm{i}, \mathrm{t}, 21]<-$ beta $[3]$ * $\mathrm{d} 1 \mathrm{Polit}[\mathrm{i}, \mathrm{t}, 21]$ * ind $[4]$ * ind $[5]$ * ind $[6]$

\}

for $(t$ in $16: T)\{$

\# d1.Political dummies for 'Other' category from 1995 onwards

product $[i, t, 15]<-$ beta[4] * d1Polit $[i, t, 15]$ * ind [1] * ind[2] * ind[3]

product $[\mathrm{i}, \mathrm{t}, 16]<-$ beta $[4]{ }^{\star} \mathrm{d} 1$ Polit $[\mathrm{i}, \mathrm{t}, 16]^{\star}$ ind $[1]{ }^{\star}$ ind $[2]$

product $[\mathrm{i}, \mathrm{t}, 17]<-$ beta $[4] \star$ d 1 Polit $[\mathrm{i}, \mathrm{t}, 17]{ }^{\star}$ ind $[1]$

product $[i, \mathrm{t}, 18]<-$ beta $[4] *$ d1Polit $[\mathrm{i}, \mathrm{t}, 18]$

product $[i, \mathrm{t}, 19]<-$ beta $[4]$ * d1Polit $[\mathrm{i}, \mathrm{t}, 19] *$ ind $[4]$

product $[\mathrm{i}, \mathrm{t}, 20]<-$ beta $[4]{ }^{\star} \mathrm{d} 1 \mathrm{Polit}[\mathrm{i}, \mathrm{t}, 20]{ }^{\star}$ ind $[4] *$ ind $[5]$

product $[\mathrm{i}, \mathrm{t}, 21]<-$ beta $[4] \star \mathrm{d} 1$ Polit $[\mathrm{i}, \mathrm{t}, 21] \star$ ind $[4] \star$ ind $[5]$ * ind $[6]$

\}

for $(\mathrm{t}$ in $1: \mathrm{T})\{$

\# d1.Time dummies

for $(\mathrm{d}$ in 22:51) \{product $[\mathrm{i}, \mathrm{t}, \mathrm{d}]<-\mathrm{b}[\mathrm{d}-21]$ * $\mathrm{d} 1$ Time $[\mathrm{t}, \mathrm{d}-21]\}$

\# d1.GDP

product $[\mathrm{i}, \mathrm{t}, 52]<-\mathrm{b}[31]$ * $\mathrm{d} 1 \mathrm{GDP}[\mathrm{i}, \mathrm{t}]$

\# time trend

product $[i, t, 53]<-b[32]$

\}\} 
\# CONVENIENT ORDER FOR SPATIAL ERROR TERM

for (i in 1:sumNumNeigh) \{

for $(t$ in $1: T)\{$

adj_error[i,t] <- error[ adj_areas[i], t]

\})

\# R-SQUARED

for (i in 1:I) $\{$ Rsq[i] <- $1-(1 / \operatorname{tau}[\mathrm{i}]) / \operatorname{pow}(\operatorname{sd}(\mathrm{d} 1 \mathrm{Y}[\mathrm{i}]), 2)$,

Rsquared <- mean(Rsq[])

\# PRIORS

\# panel-specific variances

\#for (i in 1:I) $\{\operatorname{tau}[\mathrm{i}] \sim \mathrm{dt}(0,5,1) \mathrm{T}(0)$,

for $(\mathrm{i}$ in $1: \mathrm{I})\{\operatorname{tau}[\mathrm{i}] \sim \operatorname{dgamma}(1,0.01)\}$

\# political parameters

for (d in 1:6) $\{$ ind $[\mathrm{d}] \sim \operatorname{dbern}(0.5)\}$

for $(v$ in $1: 4)\{\operatorname{beta}[v] \sim \operatorname{dnorm}(0,0.01)\}$

\# time trend / GDP parameters

for $(\mathrm{v}$ in $31: 32)\{\mathrm{b}[\mathrm{v}] \sim \operatorname{dnorm}(0,0.01)\}$

\# autocorrelation parameters

for $(\mathrm{r}$ in $1: 2)\{\operatorname{rho}[\mathrm{r}] \sim \operatorname{dunif}(-1,1)\}$

\# SELECTION OF TIME DUMMIES USING GIBBS VARIABLE SELECTION

for $(\mathrm{v}$ in $1: 30)\{$

$\mathrm{b}[\mathrm{v}]<-\mathrm{z}[\mathrm{v}]$ * ind $[\mathrm{v}+6]$

ind $[\mathrm{v}+6] \sim \operatorname{dbern}(0.5)$

$\mathrm{z}[\mathrm{v}] \sim \operatorname{dnorm}(0, \operatorname{pprior}[\mathrm{v}])$

\# stdev of 0.4 based on prior runs (without GVS)

pprior $[\mathrm{v}]<-$ ind $[\mathrm{v}+6]^{\star} 0.01+(1$-ind $[\mathrm{v}+6]) /\left(0.4^{\star} 0.4\right)$

\}) 